\title{
Una biografía intelectual y humana del profesor Luis Sánchez Granjel (Reseña)
}

\section{An intellectual and human biography of Professor Luis Sánchez Granjel (Review)}

Uma biografia intelectual e humana do professor Luis Sánchez Granjel (Revisão)

\author{
Francisco Herrera-Rodríguez \\ Francisco Herrera-Rodríguez: Catedrático jubilado (Historia de la Enfermería y Fundamentos e Historia de \\ la Fisioterapia. Facultad de Enfermería y Fisioterapia. Universidad de Cádiz) \\ Cómo citar esta reseña en edición digital: Herrera-Rodríguez, F. (2018). Una biografía intelectual y \\ humana del profesor Luis Sánchez Granjel de José María Urkia Etxabe. Cultura de los Cuidados \\ (Edición digital), 22(52). Recuperado de <http://dx.doi.org/10.14198/cuid.2018.52.23> \\ Correspondencia: Santo Domingo de la Calzada, n.ํ11-3. ․ㅡ A. 11012-Cádiz (Dirección particular) \\ Correo electrónico: fraherod57@gmail.com \\ Recibido - Aceptado: Reseña invitada
}

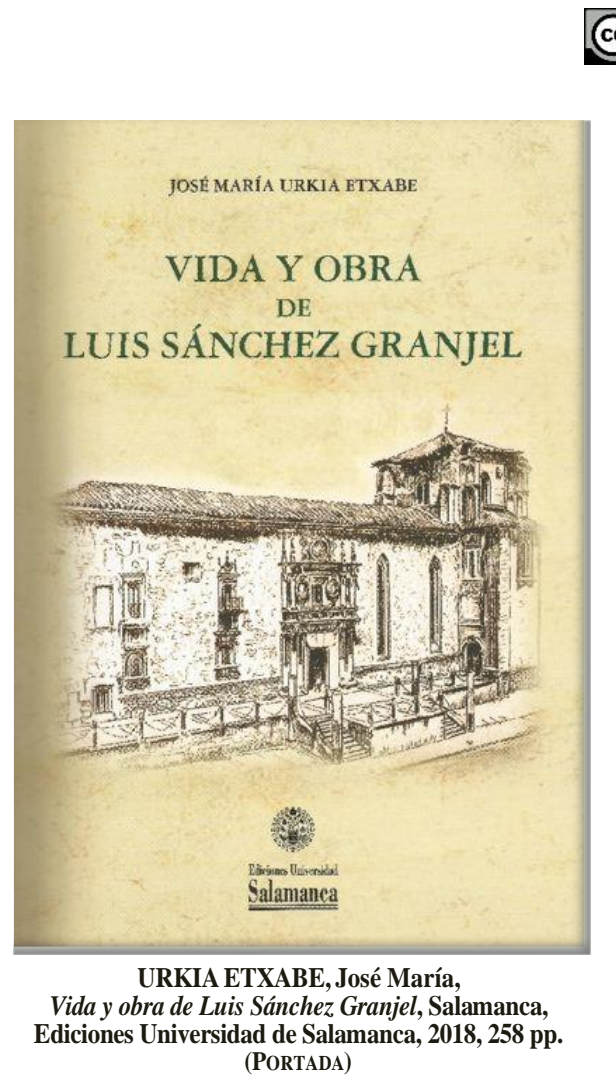

\section{ABSTRACT}

Life and work of Luis Sánchez Granjel is the human and intellectual biography of a great master of Spanish medical historiography, carried out by José María Urkia Etxabe, Professor at the University of the Basque Country. The author has counted to make this work with the documentary background of Professor Granjel provided by the family, but also the human knowledge of his figure to have been one of his most beloved disciples.

Keywords: Luis Sánchez Granjel, History of Medicine, History of Literature, José María Urkia Etxabe.

\section{RESUMO}

Vida e obra de Luis Sánchez Granjel é a biografia humana e intelectual de um grande mestre da historiografia médica espanhola, realizada por José María Urkia 
Etxabe, professor da Universidade do País Basco. O autor contou para fazer este trabalho com o fundo documental do professor Granjel fornecido pela família, mas também o conhecimento humano de sua figura para ter sido um dos seus discípulos mais queridos.

Palavras-chave: Luis Sánchez Granjel, História da Medicina, História da Literatura, José María Urkia Etxabe.

\section{RESUMEN}

Vida y obra de Luis Sánchez Granjel es la biografía humana e intelectual de un gran maestro de la historiografía médica española, realizada por José María Urkia Etxabe, profesor de la Universidad del País Vasco. El autor ha contado para hacer esta obra con el fondo documental del profesor Granjel proporcionado por la familia, pero también el conocimiento humano de su figura al haber sido uno de sus discípulos más queridos.

Palabras clave: Luis Sánchez Granjel, Historia de la Medicina, Historia de la Literatura, José María Urkia Etxabe.

José María Urkia Etxabe, donostiarra, es profesor titular de Historia de la Medicina de la Universidad del País Vasco; pero lleva toda una vida vinculado moral $\mathrm{y}$ sentimentalmente a la ciudad en la que se formó como médico, Salamanca, en la que en 1983 alcanzó el grado de doctor y en la que dio sus primeros pasos como docente: primero, en el curso 1981-1982, como Colaborador del Departamento de Historia de la Medicina, dirigido por el profesor Luis Sánchez Granjel y desde 1983 a 1986 ejerciendo como Profesor Ayudante de Clases Prácticas en la citada disciplina. En los cursos siguientes pasó a la Facultad de Medicina de la Universidad del País Vasco como Profesor Asociado (1987-1989), Profesor Titular Interino (1989-1990) y Profesor Titular Numerario, desde 1990 hasta el momento actual. Cerca de treinta años ejerciendo el magisterio de la Historia de la Medicina en el País Vasco, siempre guiado por la impronta y el sentido universitario que le inculcó su maestro, el profesor Luis Sánchez Granjel, al que ahora dedica este libro, tan necesario, que reseñamos.

Han sido años de intensa actividad docente en los que Urkia ha ofrecido a la comunidad universitaria vasca, incluso, un manual de Historia de la Medicina, escrito en euskera; pero además ha abarcado en su labor investigadora un amplio espectro de temas como el estudio de epidemias, instituciones hospitalarias y balnearias, instituciones profesionales, así como se ha interesado por figuras médicas como Gregorio Marañón, José Carrasco y Pérez Plaza, el doctor Eizaguirre, los doctores Acha, el médico humanista vasco Barriola, y recientemente por figuras médicas del Renacimiento como Miguel Servet y Andrés Vesalio. Imposible en esta reseña dar cumplida cuenta de la totalidad de su actividad publicística. A todo esto hay que añadir su implicación en la vida social del País Vasco dirigiendo la Real Sociedad Bascongada de Amigos del País o presidiendo el Colegio de Médicos de Guipúzcoa. Y también su compromiso con la Sociedad Española de Historia de las Ciencias y de las Técnicas, con la organización del XI Congreso, celebrado en Azkoitia (Guipúzcoa), en septiembre de 2011. Recordamos también los homenajes que ha llevado a cabo a grandes figuras del magisterio histórico médico español como Pedro Laín Entralgo, Juan Riera Palmero o el dedicado en el 
Colegio de Médicos de Salamanca, en 2013, a su maestro el profesor Luis Sánchez Granjel.

El profesor Granjel nació en Segura (Guipúzcoa), en 1920, y falleció en Salamanca en 2014, a la edad de 94 años. Sabemos que el profesor Urkia desde el fallecimiento de su maestro ha trabajado intensamente por convertir en realidad este libro que reseñamos: Vida y obra de Luis Sánchez Granjel. La tarea no ha sido fácil ya que los tiempos que corren son complicados para editar libros como éste, pero finalmente ha tenido el apoyo institucional y editorial de la Universidad de Salamanca, que precisamente celebra su VIII Centenario. Y también el apoyo incondicional de la familia del profesor Granjel que ha puesto a su disposición un amplio legado documental y fotográfico que ha servido para dar forma a este excelente libro, y rendir tributo de admiración y agradecimiento a su maestro. En este sentido escribe Urkia lo siguiente:

"Esta obra se basa, esencialmente, en la investigación del Archivo Personal de Granjel, 20 biblioratos, bien ordenados y repletos de una documentación preparada por el propio Granjel, años antes de su muerte y completada por sus hijos Gerardo y Mercedes, tras su deceso y a quienes agradezco su confianza por haber depositado en mis manos este legado".

También se ha utilizado el epistolario del profesor Granjel que se conserva en los Archivos del Dr. Ignacio Barriola, del Dr. Rafael Sancho de San Román y del propio José María Urkia. Por supuesto, ha tenido presente también el autor de la obra la biografía que escribió Luis Carlos Tejerizo sobre el profesor Granjel, y ha valorado muy especialmente escritos y semblanzas, por ejemplo, de Juan Riera Palmero, Diego Gracia Guillén y Antonio Carreras Panchón.

El libro está vertebrado en dos grandes capítulos: uno dedicado a la Vida y el otro a la Obra. En conjunto el libro está muy bien vertebrado, escrito con agilidad y prosa clara, acompañando el texto de una excelente colección de fotografías. En el apartado de la Vida el lector podrá conocer la infancia de Granjel en tierras vascas, los atribulados años de la Guerra Civil, el desarrollo de la carrera de medicina y como se va perfilando en su espíritu la "vocación literaria". Asimismo su ejercicio médico como psiquiatra y su paso a la vida universitaria que se consolida con la obtención de la cátedra de Historia de la Medicina de Salamanca, segunda de España, tras la de Madrid, que como es sabido desempeñaba Pedro Laín Entralgo, un referente de primer nivel en la vida intelectual y universitaria de Luis Sánchez Granjel. De igual manera, podemos encontrar su labor docente en la Universidad Pontificia de Salamanca, su participación destacada en la rehabilitación de una de las joyas del patrimonio artístico renacentista, el Colegio Mayor Arzobispo Fonseca, en el que llegaron a alojarse clérigos irlandeses católicos huyendo de la persecución inglesa de la reina Isabel I. Muy acertada, por cierto, la elección para la portada del libro de la obra del ilustrador Manuel Ángel García González. Entre las paredes de este hermoso edificio construyó Granjel una imponente obra intelectual en el seno de su Instituto de Historia de la Medicina, sobre el que escribió Pedro Laín, en 1974, lo siguiente:

"Vuelvo con el recuerdo a la Salamanca que ayer mismo he visto otra vez. Me sitúo de nuevo en el Colegio Fonseca, atravieso con calma, porque quiero gozar visualmente lo que en él contemplo y no quiero quebrar con mi ruido el tesoro de silencio de su patio. Asciendo unas escaleras de piedra y accedo a la estancia donde Luis S. Granjel ha instalado su Instituto de Historia de la Medicina (...). No hay duda, me digo; entre las consagradas al cultivo de esta disciplina, no existe en toda 
Europa una institución semejante a la que dentro del soberbio recinto por él mismo restaurado, ha sabido levantar este profesor salmantino".

En el amplio capítulo dedicado a la Vida, el profesor Urkia no pasa por alto la relación con el País Vasco y muy particularmente con San Sebastián. En este apartado llama nuestra atención un capítulo titulado "El alma de Granjel". Urkia señala la dificultad de penetrar en la profundidad del alma y el interior de una persona, "lo es también en Granjel, que mantenía una reserva muy profunda en la expresión de sus sentimientos". Urkia se esfuerza en este capítulo, exprimiendo su memoria y su trato personal con el maestro, y se apoya en otras personas que lo trataron como su entrañable amigo Ernesto Sánchez Villares que destacaba la voluntad de hierro y la tenacidad incansable de Granjel para todo lo que emprendía. O su querido discípulo el maestro Juan Riera Palmero que destacaba de Granjel, entre otros aspectos, lo siguiente: "Toda su vida se resume en dos palabras: la virtud de la templanza". Urkia también se apoya en los recuerdos de Rafael Sancho de San Román, Luis Carlos Tejerizo, Joaquín Montero, Pedro Amat, Alberto Gómez Alonso, Emilio Hernández Benito, Fermín Palma, etc. No olvida Urkia en esta parte de su libro el acercamiento al plano familiar: su esposa, Julia Santander, gran pilar de su vida, y sus hijos Mercedes, Luis y Gerardo (espléndida la fotografía en blanco y negro de la familia Granjel-Santander), y esa otra con su esposa durante la celebración del IX Congreso de Estudios Vascos (Bilbao, 1983). Para profundizar en ese Granjel "íntimo" recomendamos la lectura del capítulo "Granjel y Barriola: epistolario". En una de esas cartas escribe Granjel: "El vacío literalmente me horroriza. Tengo que escribir algo, lo que sea, aunque tenga la certeza de que no se publicará..., sin eso supondría que la vida, para mí, habría concluido". En este sentido cabría recordar las palabras de Antonio Carreras Panchón, en el emotivo homenaje que en 2013 le fue dedicado en Salamanca:

"Si hay una característica que domine la vida de Granjel es su condición de trabajador infatigable, impenitente, obstinado, casi compulsivo. Cuantos hemos estado cerca de él, no hemos podido menos de sorprendernos de esa capacidad para superar las adversidades más penosas de la vida, -y en la suya ha habido momentos de una dureza que para muchos resultarían insoportables-, a base de trabajo y compromiso con que considera es la razón última de la vida de un hombre".

El libro cuenta con un segundo "bloque" en el que se analiza la Obra granjeliana, incluida la dedicada a la Psiquiatría, destacando claro está su legado como gran estudioso de la literatura española, por ejemplo, de los grandes y pequeños escritores del 98, así como su ingente labor de investigación de la historia de la medicina española, que muchos autores suelen calificar como "un antes y un después" en la historiografía médica de nuestro país. El lector interesado podrá conocer el quehacer de Granjel en sus trabajos dedicados a la historia de la medicina vasca, pero también su labor en el contexto de la historia de la Psicología, de la Geriatría y de la Gerontología. Asimismo Urkia dedica algunas páginas de su libro a la relación de Granjel con instituciones como la Real Sociedad Bascongada de los Amigos del País, el Centro de Estudios Salmantinos, la Real Academia de Medicina de Salamanca y la Real Academia Nacional de Medicina, institución esta última en la que ingresó en marzo de 2003 y a la que dedicó su inteligencia, laboriosidad y pasión en los últimos años de su vida, entregando a la imprenta trabajos muy importantes de los cuales solo 
destacaremos aquí su Historia de la Real Academia Nacional de Medicina (2007 y 2010), que como señala Urkia "es la primera historia completa realizada por un profesional en donde rehace el pasado de la Academia entre 1733 y 2000", utilizando como fuentes documentales las Actas y el Archivo, constatándose "la evolución de la Institución con etapas de auge y decadencia en función de la vida social española".

La parte final del libro contiene un pormenorizado catálogo de la obra histórico-médica y literaria del profesor Granjel, vertebrado de la siguiente manera: I. Historia de la Medicina Española; II. Publicaciones del Instituto de Historia de la Medicina Española (Director: Prof. Dr. D. Luis S. Granjel); III. Historia de la Medicina Vasca; IV. Otros trabajos; V. Historia de la Gerontología y la Geriatría; VI. Obra Literaria; VII. Prólogos. Y, por último, un apartado final de Bibliografía en el que destacan, entre otras, las autobiografías de Granjel, la biografía de Luis Carlos Tejerizo, los obituarios realizados en 2015, respectivamente, por Diego Gracia y Juan Riera, la relación de los epistolarios de Granjel con Rafael Sancho de San Román, Ignacio María Barriola Irigoyen y José María Urkia Etxabe, y sobre todo un desglose documental de las 20 cajas del Archivo personal del profesor Granjel. Este pormenorizado catálogo le da al libro de Urkia un valor añadido y lo convierte en un imprescindible "Vademecum" para futuros investigadores de la vida y obra de este gran maestro de la historiografía médica española.

Un maestro, Granjel, que trae a mi mente una conocida frase de Séneca: "Pero ten cuidado, no sea que la lectura de tantos autores $y$ de todo género de libros tenga algo de vago é inestable. Conviene detenerse y nutrirse de ciertos ingenios si queremos obtener de ellos algo que se adhiera sólidamente á nuestro ánimo". Urkia afianza más, con este libro, la convicción que anida en las mentes $y$ corazones de muchos historiadores españoles de la medicina y de la literatura, que la obra de Granjel (rememorando el conocido título de Huarte de San Juan) es la de un ingenio que merece examen.

Urkia, a través de sus palabras, o de las de otros que trataron y conocieron a Granjel, nos ha transmitido que, como decía Séneca, lo importante es llevar consigo bienes como la justicia, la virtud, la prudencia y la templanza. Bienes que abundaban en las alforjas de Granjel y que, sin duda, también se reflejan en su obra.

Urkia suo Granjel salutem. 